\title{
Article
}

\section{Social workers' perception of practice with lesbians, gays and bisexuals (LGBs) in Nigeria}

by

Elizabeth Onyedikachi George

Graduate Assistant

Department of Social Work, University of Nigeria

Nsukka, Nigeria

E-mail: elizabeth.george@unn.edu.ng

ORCID iD: https://orcid.org/0000-0001-5678-4113

Prince Chiagozie Ekoh

Graduate Assistant

Department of Social Work, University of Nigeria

Nsukka, Nigeria

E-mail: princechiagozie.ekoh@unn.edu.ng

ORCID iD: https://orcid.org/0000-0002-1787-536X

\section{Keywords:}

homosexuality, LGBs, homophobia, social work, Nigeria, qualitative research

DOI: https://doi.org/10.31265/jcsw.v15.i2.306

\section{(c) (i) (2)}

This work is licensed under a Creative Commons Attribution-ShareAlike 4.0 International License. 


\section{Abstract}

People from Low-to-Middle-Income Countries (LMICs) like Nigeria, irrespective of differences in beliefs and sexual orientation, face similar challenges in terms of living standards, access to resources and quality of life. However, people who have been 'othered' on the basis of their nonconformity to heteronormativity face additional challenges. The existence of the Same-Sex Marriage (Prohibition) Act (SSMPA) of 2014, which criminalizes the normalization of homosexual 'lifestyles' and the persistence of a homophobic socio-political climate in Nigeria, exposes lesbians, gays and bisexuals (LGBs) in Nigeria to unique difficulties. Although social workers are expected to work, guided by the values of social justice and respect for human rights, with the vulnerable and oppressed in society such as LGBs, the socio-political contexts they operate in can limit how well they do this work. This paper seeks to explore the views of social workers on social work practice with LGBs in Nigeria, with qualitative data obtained from 12 professional social workers using in-depth interviews that were thematically analysed. Findings show that social workers' perception of practice with LGBs in Nigeria is influenced by existing policies in the country, in addition to cultural and religious beliefs. Some social workers also view LGBs through a medical perspective of homosexuality being an illness, which can affect their work with this population. Recommendations from the study include developing a contextualized ethical code that addresses practice dilemmas and further research centred on the experiences of LGBs and social work practice, as this is one of the few studies on social work practice in Nigeria with this population.

\section{Keywords}

homosexuality, LGBs, homophobia, social work, Nigeria, qualitative research 


\section{Introduction}

Heterosexuality is largely considered the appropriate and healthy way of being in Africa, and any expression of sexuality deviating from this norm is seen as immoral, abnormal, and in many countries, illegal (Jacques, 2014; Oginni et al., 2018). Homosexuality is considered a Western import, and thus an affront to traditional African cultures and values, including those influenced by Christian and Muslim religions, the dominant religions on the continent (Epprecht, 2012). Although South Africa was the first country in the world to legally prohibit discrimination based on sexual orientation (Jacques, 2013), leading the way for African countries like Botswana, Cape Verde and Mozambique to legally protect sexual minorities from discrimination, there still exists, in many other African countries, such as Nigeria, Uganda, Burundi and Zimbabwe, anti-homosexuality laws established in a bid to 'protect' Africa from Western cultural imperialism (Epprecht, 2012; Epprecht, 2013). While Nigeria is very heterogenous with diverse, and sometimes polarizing religious beliefs, political affiliations and cultures, this diversity appears to be unified by the strong stance against same-sex attraction and behaviours (Epprecht \& Egya, 2011).

Nigerian society largely holds on to the position that homosexuality contradicts the cultural and traditional values of the society. The Pew Research Center (2013) reveals that only $1 \%$ of Nigerians agree that homosexuality should be societally accepted. Homosexuals are considered by the majority in Nigeria to be deviants (Nalah \& Ishaya, 2013), sinners (Finnish Immigration Service, 2015), Satanpossessed and un-African (Arimoro, 2018). This position is endorsed by the country's major religions and laws (Nigeria, 1990, 2014). In light of the legal and societal restrictions to the rights of people with same-sex attraction, we sought to explore social work with lesbians, gays and bisexuals (LGBs) in Nigeria by examining how a sample of professional social workers perceive working with LGBs in Nigeria. Our study was guided by the question: How do social workers in Nigeria understand homosexuality and perceive working with LGBs? Since the antagonism towards sexual minorities in Nigeria is primarily focused on those concerning same-sex orientation: homosexuality and bisexuality (Nalah \& Ishaya, 2013), our study was limited to LGBs. Thus, in this article, LGBs and homosexuality are used as umbrella terms to refer to lesbians, gays and bisexuals, and their sexual orientation. 


\section{Literature Review}

Nigeria's firm stance against homosexuality and homosexuals/bisexuals is informed, not just by cultural values indigenous to the country, but also by the values of the British colonialists (Arimoro, 2019) and the value systems of the country's two dominant religions, Christianity and Islam (Ayeni 2017, as cited in Arimoro, 2019). In signing the Same-Sex Marriage (Prohibition) Act 2013 (SSMPA), which criminalizes same-sex unions and public relationships by imprisonment (Nigeria, 2014), the Nigerian government re-echoed the country's stance against homosexuality (Nigeria, 1990; Ottoson, 2010). The SSMPA not only encourages discrimination and persecution of LGBs (Arimoro, 2019), but discourages support of allies citing a 10year joint sentence for anyone 'who administers, witnesses, abets or aids the solemnization of a same sex marriage or civil union...' (Section $5(3)$ ).

Due to the hostility of the country's political and sociocultural climate towards sexual 'divergence', LGBs live with psychosocial stresses. Oginni et al., (2018) showed an increased depression rate among gay Nigerian students, brought on by childhood gender atypical behaviour, parental neglect and low resilience. LGBs in Nigeria are encumbered with worries about protecting their identities and lives, finding love and sexual partners without endangering their lives and gaining acceptance by their friends, families and communities (Epprecht, 2013; Jacques, 2013; Jacques, 2014; Oginni et al., 2018; Arimoro, 2019). The homophobic culture prevalent in Nigeria also exposes LGBs to hateful attacks (Gay News, 2010; Immigration and Refugee Board of Canada, 2012; Daemon, 2016; Human Rights Watch, 2016; Arimoro, 2019).

Despite the declassification of homosexuality as a mental illness by the American Psychological Association (APA) in 1973, it is still accepted around parts of the world, including Nigeria, that homosexuality is caused by underlying psychological and environmental challenges, and can thus be cured through psychological interventions (APA, 2009; Teh et al., 2018), which may lead to more stress. Also, similar to many other populations, LGBs in Nigeria face other economic and psychosocial challenges brought on by a low standard of living and quality of life in the country; however, they face more challenges finding employment, getting unrestricted access to economic resources and quality healthcare services (Finnish Immigration Service, 2015). The challenges they face living as both sexual minorities and ordinary Nigerians 
necessitate the intervention and advocacy of social workers and other psychosocial professionals. Hence, social workers find themselves in situations where they have to provide social services to LGBs (Vinjamuri, 2017) in a safe and non-discriminatory environment (McNair \& Hegarty, 2010; Teh et al., 2018).

Although social work has yet to attain full professional status in Nigeria, owing to the federal government's position on the professionalization of social work (Okoye, 2014; Ogbonna, 2018), there are university departments and schools of social work across the country offering undergraduate and postgraduate programmes designed to train prospective social workers on working with vulnerable people (Mbah et al., 2017). Social workers in Nigeria encounter and work with service users in remand homes for children, social welfare agencies, prisons, schools, communities, NGOs and healthcare settings (ibid.). While social workers in Nigerian healthcare settings are much more likely to encounter LGBs who seek HIV treatment and support services (Human Rights Watch, 2016), workers in other settings can still work with- and provide services to LGBs in Nigeria. Nonetheless, the academic trainings social workers receive fail to specifically prepare them for working with this population. In many schools and departments of social work, the educational and practice curricula include little to nothing on homosexuality and/or working with LGBs (University of Nigeria, 2020), something the authors can testify to, having gone through social work undergraduate training in Nigeria. This, and the absence of studies on teaching about homosexuality in Nigeria and Africa (Epprecht \& Egya, 2011), may point to the unpreparedness of social work students and consequently, social workers, in working with LGBs.

Whereas the social work profession stands against discrimination on the basis of sexual orientation, and promotes respect for diversity and human rights (International Federation of Social Workers, 2014; Jaffee, Dessel, \& Woodford, 2016; National Association of Social Workers, 2017), social workers in Nigeria may find it difficult working to protect the rights and well-being of LGBs because they lack the competencies to do so, while navigating the laws and dominant values standing in opposition to homosexuality. While the values of the profession mandate social workers to challenge positions restrictive to the rights and well-being of individuals and groups, such as LGBs (Jacques, 2014), this may be nearly impossible to do for 
professionals who belong to societies that uphold discriminatory values (Collins, Jordan, \& Coleman, 2013), and by reason of socialization, may also hold on to such values themselves. The tensions between social workers' personal and cultural values that are unaccepting of sexual diversity, and their professional values which promote an acceptance of LGBs, can make it challenging for social workers to work competently with these groups (Dessel \& Bolen, 2014; Fallon et al., 2013; Hepworth et al., 2013).

As a result of the existing laws and societal beliefs antagonistic toward LGBs, some social workers may feel they are betraying their religion, cultural heritage and country, as well as risking their lives and reputation, by working to meet the needs of LGBs in Nigeria. This reveals the influence of the social environment on individuals and their ways of being, as posited by Person-in-Environment theory (Weiss-Gal, 2008), and demonstrates the importance of specific training for professionals in Nigeria on competently working with LGBs and responding to their needs, while also successfully navigating the tensions faced due to existing context-influenced differences between their personal and professional values (Jacques, 2014; McCartyCaplan, 2018; Teh et al., 2018).

Studies have examined experiences of LGBs in Africa (Epprecht, 2013; Jacques, 2014), social work with LGBs in Africa (Jacques, 2013; Jacques, 2014) and the experiences of LGBs in Nigeria (Akogwu, 2018; Arimoro, 2018; Arimoro, 2019; Oginni et al., 2018). However, there is a dearth of literature on studies exploring social work with LGBs in Nigeria. This study addresses this gap in knowledge by examining how social workers in Nigeria perceive social work practice with LGBs. In giving voice to social workers in Nigeria who face value and legal conflicts in their duty towards this vulnerable group, this study provides a starting point for more research and for Nigerian social work institutions and associations to develop and implement contextualized and indigenous professional trainings, in addition to ethical codes to guide Nigerian social workers in working with LGBs.

\section{Methodology}

This study was conducted qualitatively, as qualitative studies are best suited for exploring varying understandings and viewpoints individuals hold on to (Hammersley 
\& Atkinson, 2007; Bryman, 2016). Because of the exploratory nature of the study, we decided not to impose a theoretical framework in designing the study (Gobena \& Hean, 2019), but instead adopted a qualitative inductive approach to both allow for flexibility in methodological choices, and to let findings and themes emerge freely from the data (Bryman, 2016; Gobena \& Hean, 2019). The in-depth exploration and understanding availed by the qualitative method gave us a better grasp of the contexts and varying understandings/beliefs of social workers who participated in this study concerning practice with LGBs in Nigeria.

\section{Study Population and Sampling}

This research was centred on social work in Nigeria; consequently, the population for the study was selected from social workers who live and work in Nigeria. According to estimates by the Nigerian Association of Social Workers (NASoW), there are 4,000 registered social workers in Nigeria (IFSW, 2020). A purposive sampling was used to select participants from this population who can provide detailed information (Bryman, 2016) on their perception of social work with LGBs in Nigeria. In selecting participants, we took into consideration various demographic elements, such as age, gender, level of education and years of practice, in order to have participants from different demographic categories.

We sought to include workers representing major regions and religious groups in Nigeria, drawn out from different areas of practice (medical social work, school social work, rehabilitation, private practice and community development work). We did not consider years of experience working with LGBs as a required criterion because of the fear attached to the criminalization of homosexuality, and consequently, the difficulty of finding professionals who would admit to working with LGBs.

Requests for participation were sent out to 15 social workers in our networks who work in different settings of practice, and who would be willing to discuss sexuality, seeing that sex is generally an off-limits subject in Nigeria. The choice of 15 workers was made because this was a small-scale independent study without external funding. The 12 participants who accepted our request were selected to participate in the study, with the table below showing their demographic characteristics. 
Demographic characteristics of participants

\begin{tabular}{|l|l|l|l|l|r|l|}
\hline Pseudonyms & Gender & Age & $\begin{array}{l}\text { Level of } \\
\text { education }\end{array}$ & Religion & \multicolumn{1}{|l|}{$\begin{array}{l}\text { Years of } \\
\text { practice }\end{array}$} & Area of practice \\
\hline Emeka & M & 30 & M.sc. & Christian & 7 & School social work \\
\hline Halima & F & 28 & M.sc. & Muslim & 5 & School social work \\
\hline Enweremchi & F & 38 & Phd & Christian & 13 & Rehabilitation \\
\hline Timilayo & M & 27 & M.sc. & Christian & 6 & Child welfare \\
\hline Itorobong & M & 32 & B.sc. & Christian & 4 & Family services \\
\hline Bisola & F & 36 & M.sc. & Muslim & 14 & Medical social work \\
\hline Riftatu & F & 33 & M.sc & Muslim & 8 & Private clinical practice \\
\hline Yetunde & F & 30 & M.sc. & Muslim & 6 & School social work \\
\hline Chidiebere & M & 28 & B.sc. & Christian & 6 & Medical social work \\
\hline Chinaecherem & F & 31 & M.sc. & Christian & 10 & Community development \\
\hline Lami & F & 27 & M.sc. & Muslim & 7 & School social work \\
\hline Amadi & M & 35 & P.hd & Christian & 12 & Community development \\
\hline
\end{tabular}

\section{Data Collection}

In-depth interviews were chosen for this study, considering their fit for exploratory studies (Bryman, 2016; Hammersley \& Atkinson, 2007) such as this; it helped us explore participants' understanding and extract meaningful information from them. The interviews were semi-structured to fit into the inductive nature of this study, and let discussions flow freely, exploring areas of discussion more interesting to participants. The interviews were conducted in November 2019 using telephone calls, because of the proximity between us and participants at the time of data collection.

Although telephone interviews may be considered to be an inferior data collection tool by some qualitative researchers, they are an emerging and necessary qualitative tool in the $21^{\text {st }}$ century (Drabble et al., 2016; Novick, 2008), especially with the rising preference for physically distant meetings. Using telephone calls did not prove extremely difficult, particularly because the interviews were conducted with social workers, with whom we had had preliminary contact. The 'blindness' created by using phone interviews helped for an ease of discussion, and allowed the participants to freely give their opinions on social work with LGBs, a controversial area of discussion in Nigeria. The interviews were recorded using an electronic recording device, and notes were taken during and after the interviews. 


\section{Analysis}

The recorded data was transcribed as verbatim as possible. The transcribed data was analysed using a thematic analysis, which involved finding out, interpreting and reporting patterns of meaning with data (Braun \& Clarke, 2006; Ritchie et al., 2014). An inductive approach was adopted, allowing codes to occur to us in the process of reading the transcript without a pre-existing code created in advance. This was done using Nvivo 12.

Using a constant comparison within and between cases, the content of the codes was compared, and proliferated codes were merged. Codes with common elements were combined into a hierarchy to produce coding trees. Robustness was tested by going back to the data fragments, interviews with field notes and full transcripts to view the original quotes in their contexts. The relationship between the codes and the research question was explored; labels with an adequate reflection of the codes that underpin them (Bryman, 2016) were given to themes. We wrote up the findings, and discarded those themes without enough evidence to support them.

Pseudonyms were assigned to the participants to ensure anonymity and confidentiality, while at the same time humanizing them. Labels were also given to them as a form of identification in quotes reporting (Willis et al., 2016) according to their gender: Male (M), Female (F), pseudonyms and years of practice. For instance, the label 'Halima, F, 5' refers to a female social worker named Halima, who has practiced social work for five years.

\section{Trustworthiness and Ethical Considerations}

In the absence of standardized tools for measuring the validity and reliability of qualitative research, we employed different strategies to ensure trustworthiness, addressing how credible, transferable, conformable and dependable our research findings were (Morrow, 2005). We did this by taking on a standardized methodology, conducting the study in a familiar context, giving no incentives for study participation, having no predetermined research findings and not focusing on generalizations, but instead providing rich descriptions of the research context and participants to allow for comparisons with other contexts in which transfer may be contemplated and judging each other's contributions to the study to help ensure a degree of neutrality 
(Morrow, 2005; Bailey, 2007; Gobena \& Hean, 2019). Study participants had a good understanding of the interview questions, and answered freely and articulately.

The research was conducted in line with ethical principles and considerations for social work, social research and qualitative research, to ensure the trustworthiness of the research and findings and the protection of the participants' rights and identities (Bryman, 2016; Deane \& Stevano, 2016; NASW, 2017; Pittaway et al., 2010). Participants were duly informed of the research and consented to participate, of their own volition. Measures were taken to protect the rights and identities of the study participants, with ethical clearance for the study sought from the University of Nigeria Teaching Hospital.

\section{Results}

Three themes emerged from the analysis of workers' perception of social work with LGBs. The themes are related to their subjective feelings and views about homosexuality, factors that influence their views, and how the views they hold may affect their practice with LGBs.

\section{Social workers' feelings and perceptions of homosexuality}

This theme shows sampled Nigerian social workers' feelings about- and understanding of homosexuality. First, our analysis revealed that their feelings about homosexuality are somewhat complex, because while many of them feel it is morally wrong to be homosexual, they do not want to be perceived as judgmental social workers. They described their individual perception of homosexuality differently from their professional view about it. Thus, irrespective of their personal opinions, they still want to respect other people's sexual orientation:

I feel it's not something I would subscribe to... I just don't feel okay with it. You know in terms of sexual orientation I feel it's not okay. For me o! ...I don't condemn it, what I mean is if somebody's sexual orientation is this, I will not come out and tell the person that it's totally bad and he is doing a bad thing but for me, I feel it's something I.... I can't imagine. (Timilayo, M, 6)

I wouldn't judge somebody for their preference of sexual partners or sexual lifestyle because the profession doesn't support that, and if I were to call myself a social worker and I still go ahead and label people then it means I will not be successful in my career. But if I were to be asked personally if I have anything against homosexuality, my first answer will be yes. I don't think it is normal as a person. (Halima, F. 5) 
However, some of them were straightforward with their views about their total rejection of homosexuality. They believe it is abnormal and wrong, and that there is no justification for people to engage in same-sex relations. They consider homosexuality unacceptable irrespective of social work's emphasis on human rights and freedom. They highlighted that homosexuality is an effect of globalization: Nigerians learned homosexuality through exposure to Western lifestyle

Homosexuality is not an African thing, it is not of any value in Africa and I am a Nigerian. I'm a typical African woman, so our orientation, our value system does not support homosexuality. So, I have never...it's a new thing, it was learnt, just like a borrowed culture from a white man's country. So, because of that, because my culture does not accept or condone it. I do not accept it, yeah, it's against my belief system, as a Nigerian and as a social worker. (Chinaecherem, F, 10)

Contrary to the views above, three of the respondents emphatically stated that they do not have any negative feeling about homosexuality, irrespective of the culture which opposes it in Nigeria, and completely believe that everyone should have the right to choose whom they love or want to have sexual relations with. 'We accept homosexuals the way they are, even though our culture being Nigerians don't accept it.' (Lami, F, 7)

Furthermore, participants expressed diverse views on the causes of homosexuality. Some identified it as a biological abnormality resulting from a hormonal imbalance and gender disorder, whereas many saw it as environmentally induced. They argued that children are born 'tabula rasa' (blank/empty-minded), but learn their sexual behaviours through socialization. They opined that people 'learn' homosexuality through social media and exposure at younger ages to homosexuality-rife environments. Many participants cited the example of young girls in female-only secondary schools learning lesbianism from other girls in school:

Okay. I think in fact... $80 \%$ of their behaviour in terms of homosexuality is learned. You understand? It is due to their environment where eh- they see that other people are doing it and enjoying it and they had to go into it. (Emeka, M, 7)

In addition to the social learning of homosexual behaviour, sexual abuse, child molestation and heartbreak, traumatic experiences in romantic relationships were further identified as causal factors of homosexuality. Some participants stated that many LGBs were either sexually abused as kids or had terrible experiences with 
people of the opposite sex, which changed their sexuality. 'Some of them were abused when they were in secondary school or at home' (Bisola, F, 14).

Some participants also reported that people become homosexual for economic benefits. They argued that LGBs receive money in exchange for same-sex sexual relations. Some maintained that wealthy homosexuals entice others to become gay by promising them economic empowerment. This opinion might be informed by Nigeria's poverty and capitalist outlook, as everything seems to be designed for economic benefit. A participant narrated:

Maybe because they want to get money and those people promise them a lot of goodies like... Like the guy I just mentioned, they opened a business for him, they gave him money to buy OK [imported vintage clothes] ...Before he joined the club [of homosexuality], he was not doing anything, it was the club members that actually sponsored him to become who he was before he died... if this guy had money, if he had something doing... they wouldn't have lured him into homosexuality. (Yetunde, F, 6)

Participants' views about how people 'become' gay influence their stance on its curability. They argued that same-sex attraction can be changed through medical treatments to correct hormonal imbalance, and rehabilitation and counselling to change learned behaviours. Some also opined that LGBs can be helped spiritually through prayers. Many respondents portrayed homosexuality as an abnormality requiring treatment:

....those people, they have a serious hormonal imbalance and medically they can be assisted. And there are some people who are into homosexuality, for instance ladies who are into lesbianism... because of an aftermath of broken relationships...so people who are in this category, with serious counselling and a lot of psychotherapy, they can be made to understand that because you having a broken relationship doesn't mean you should change your sexual orientation. (Timilayo, M, 6)

The narratives above show that the majority of the sampled social workers are prejudiced against homosexuality, although their profession prevents them from judging or discriminating against LGBs. These narratives also reveal many misconceptions about homosexuality, which might be because Nigeria is a society where people shy away from discourses around sex and sexual orientation; this is reflected in the little amount of research interest to acquire and produce more knowledge about the subject matter. 


\section{Factors influencing social workers' perception of homosexuality}

This theme highlights the various factors influencing the workers' views about homosexuality. Our analysis showed that socio-cultural factors bordering around religious beliefs and culture majorly fuel their positions concerning homosexuality. Many argued that homosexuality deviates from their culture as Africans and Nigerians, and is a borrowed culture which their religions (Christianity and Islam) strongly oppose. 'Even my faith does not support homosexuality, my faith does not support it and I'm a person of faith' (Yetunde, F, 6):

...it is not part of our culture, and because it is not part of our culture, Nigerian law doesn't support that...yes, my religion doesn't support that, my belief system and our cultural practice doesn't support that and because of that, I do not support it oooo, I don't, it is evil. (Enweremchi, F, 13)

Moreover, the SSMPA, which criminalizes homosexuality in Nigeria, also influences participants' perception. They believe that the criminalization of homosexuality by Nigerian policymakers means it is morally wrong. However, many respondents feel the penalty of incarceration for 14 years is inhumane; they opined that homosexuality could remain a crime only with a more humane rehabilitation-focused penalty. 'Taking that person to serve 14 years imprisonment, it doesn't make sense. It affects social workers' views and it also affect our practice in order to help them' (Chidiebere, $M, 6$ ).

Social work professional training was also found to affect the workers' thoughts about homosexuality. Those who attested to accepting people of different sexual orientations emphasized being influenced by social work principles and values. They used terms like 'acceptance', 'non-judgmental attitude', 'self-determination', 'respect for dignity and worth of persons', 'freedom and right of association' and 'social workers ethical responsibility to service users' to support their anti-discriminatory stance on homosexuality:

You know as a social worker we were trained to be non-judgmental, so I think my view on this homosexuality stuff, I don't think it will be right for a social worker to actually judge anybody based on what anybody wants to choose in terms of their homosexuality. (Riftkatu, F, 8)

Nigeria is a very religious country; as a result, religion and culture influence the views of people irrespective of their profession. However, exposure to social work education is slowly influencing the social workers' positive perception about LGBS, leading to their (LGBs) improved acceptance. 
Social workers' perception of practice with homosexuals

This theme reveals how social workers' perception of homosexuality and the factors influencing their views are connected to their perception of working with LGB service users. Some workers reported they will experience value conflict when working with LGBS, stating that since their culture and religion oppose homosexuality and that Nigerian law criminalizes it, it will be difficult and even wrong for them to work with this group. Even so, they do not think it right to report a service user who confides in them about their sexuality. But they believe the conflict of values would affect their working relationship, so they would rather refer the service users to other social workers who they believe to be more accepting of LGBs:

Well, it [homosexuality] will affect my relationship with the client, of course. I'll have to withdraw myself from the client, because it is not right and I wouldn't want anything that will influence my thinking or my relationship with them...It will also make me not provide any help or assistance to the person....what I can do is to refer. (Enweremchi, $\mathrm{F}, 13)$

Some participants revealed that working with LGBs may influence their own sexuality, while others stated that they might be exposed to the risk of being sexually abused. They recounted stories of LGBs who were sexually frustrated because of the criminalization of homosexuality, thereby resorting to unacceptable sexual acts like rape and the molestation of children when they had intense sexual urges:

Well if I should work with someone who is homosexual...I think it's not going to be very easy for me 0 , kai [expression of disapproval]...I learned that even, some of them, when they get to their horny mood, they can grab you. (Amadi, M, 12)

If I have to work with a male service user who is a homosexual, and I'm a male and he's a male and when he gets horny, especially when he sees you that you have this robust buttocks, the person may drag you, if you're in an isolated place for the interview or where you want to do intervention. The person may want to, should I call it rape or violently have sexual intimacy with you. So I think I don't wish to work with them ... But if I have to, I have to be extremely careful. (Emeka, M, 7)

This position led one participant to argue for male social workers only accepting lesbian services users, while female social workers accept gay men service users to protect workers from sexual relations with service users. However, the participant did not consider that some service users might be bisexual and most importantly, that it is unethical for social workers to have sexual relations with service users, irrespective of their sexual orientation:

Now if you're working with someone, if you're a man working with an opposite sex who is a homosexual, maybe for instance l'm a man working with a woman who is 
homosexual, I don't think there is a problem, but if you're working with the same sex (laughs) my recommendation is to run for your life (laughs). (Emeka, M, 7)

The narratives above show that culture, religion and the SSMPA all contribute in influencing the social workers' perceptions of homosexuality and consequently, their view of working with LGB service users. They also hold the view that working with LGBs will be difficult because they fear being influenced or sexually violated by them. Yet, it is also worth noting that some participants who stated their disapproval of homosexuality maintained that they would have no problem working with LGBs. They argued that their professional values take precedence over their personal values; therefore, they will not experience conflict of values in their working relationship with LGB service users:

...it is my primary responsibility, first and foremost, not to judge any client or patient, okay? So even if I have my own personal reservations about their sexual orientation, I cannot express it while working with them, yeah. I can't because my profession prohibits that. I'm going to just face the case before us, the problem at hand and deal with the individual objectively and empathetically. I am not going to bring in my own personal uh---bias into it. (Riftkatu, F, 8)

\section{Discussion}

This paper explores 12 social workers' views on working with LGBs in a homophobic country like Nigeria. It contributes to a small body of literature on social work with LGBs in Africa (Jacques, 2013; Jacques, 2014), and is the first of such a study in Nigeria. It reveals that social workers have been socialized into the homophobic culture prevalent in Nigeria (Nalah \& Ishaya, 2013); this raises a conflict between their professional values which emphasize acceptance, social justice, nondiscrimination and respect for persons' worth and dignity irrespective of differences (IFSW, 2014) and their personal values, which stand against homosexuality. This invariably has implications for their practice with LGBs (Teh et al., 2018).

\section{Products of the environment}

Human beings are a product of their environment; hence, social workers are highly influenced by their environment. This is evidenced by participants arguing that they will be less African and less Nigerian if they accept homosexuality. The prevalent culture in Nigeria is one that views divergence from heterosexuality as morally wrong and un-African (Arimoro, 2018), with the two major religions in Nigeria (Christianity and Islam) considering same-sex attraction and relations sinful (Arimoro, 2019). These workers were therefore socialized from childhood to believe people must be 
heterosexual, and think of homosexuality as a taboo and LGBs as immoral, biologically abnormal and/or un-African (Arimoro, 2019; Epprecht, 2012; Epprecht, 2013). Thus, for social workers in Nigeria to be accepting of LGBs, they have to deviate from the cultural and religious positions they have been socialized into.

The criminal: When loving becomes a crime

In addition to the sociocultural situation in Nigeria that encourages discrimination against LGBs, there is no legal protection for these people; instead, Nigeria like some other African countries, have enacted anti-LGB laws in an attempt to maintain African culture and values (Epprecht, 2012; Epprecht, 2013). The position of the Nigerian law, with SSMPA criminalizing homosexuality (Arimoro, 2019), further complicates the already-existing conflict of values for social workers: They are now caught inbetween personal values (influenced by culture and religion), the law (which should be respected as part of social workers' ethical responsibility to the society) and their professional values (Jaffee et al., 2016; NASW, 2017).

\section{The professionals' dilemma}

These conflicting values, between the unaccepting environment (culture and law) and professional values that emphasize acceptance, affect social workers' views on working with homosexuals (Dessel \& Bolen, 2014; Fallon et al., 2013; Hepworth et al., 2013). This is why some social workers argued that it will be very difficult for them to work with LGB service users, because their working relationship may be affected by the value differences (Collins et al., 2013), while some insisted that they can only refer the service users to other social workers more open-minded about homosexuality. This may not only deny LGBs needed quality services from competent social workers, but may also cause more psychological stress if they sense that a profession that should protect them also discriminates against them. Additionally, in respecting the law of the country and conforming to the ideals of the Nigeria culture, social workers are faced with a situation in which professional ethics and values expected to be universally adopted by all social workers (Jacques, 2014) are neglected. 
Contamination of sexual orientation: The result of misunderstandings

The social workers sampled in this study believe homosexuality is caused by underlying psychological and environmental factors, with some believing that psychosocial or spiritual interventions can change LGB's sexuality to heterosexuality (APA, 2009; Teh et al., 2018). They also reported being worried that working with LGBs may affect their own (social workers') sexuality. Participants expressed fears about LGB service users influencing them into becoming homosexuals or endangering them, as sexually-frustrated homosexual service users may molest them. This may be informed by misconceptions about LGBs and tall tales of LGBs acting sexually inappropriately (Human Rights Watch, 2016; Dentato et al., 2018; Arimoro, 2019).

\section{The professional: Impact of professional training}

Social workers' professional values and ethics, which emphasize non-discrimination irrespective of sexual orientation (Jaffee et al., 2016; NASW, 2017), was found to influence some social workers' views about LGBs. Those who indicated acceptance of LGBs cited social work professional training and core values as the rationale for their acceptance. Some social workers indicated that they do not support homosexuality, but would accept working with them because the professional values they were trained on take precedence over their personal bias and prejudice; they respect the core values of social justice, non-discrimination and respect for persons' worth and dignity irrespective of sexual orientation (IFSW, 2014; Jaffee et al., 2016). This highlights the importance of social work training as a tool for a total inclusion and acceptance of diversity (Jacques, 2014; McCarty-Caplan, 2018).

\section{Limitations}

Many social workers were not very comfortable discussing the topic because of the culture in Nigeria, where sexuality and homosexuality are seldom discussed; this influenced the small sample size $(n=12)$, which is not very representative of social workers' population in Nigeria, nor of social workers who may be working with LGBs. For this reason, this study's findings should be interpreted with caution, since the aim is not to generalize. 


\section{Conclusion and recommendation}

This study shows that some social workers in Nigeria have a poor knowledge of homosexuality, and hold views that are considered homophobic. Their poor acceptance of LGBs is supported by the country's legal, cultural and religious systems. Social work practice with LGBs will therefore be challenging, as social workers are wary of working with a group recognized as deviants in society, despite social work's emphasis on acceptance, non-judgmental attitudes and nondiscrimination. Based on these, we recommend that:

Practice with LGBs and other minority groups should form part of the social work curriculum, so that social workers in Nigeria will have a clear understanding of how to work with sexual minorities. This can be achieved through social work education, incorporating a research practicum to provide opportunities to integrate research theory with practice. This will help develop a broader knowledge and skills on working with LGBs, which can aid in reducing negative stereotypes.

Research evidence on sexual minorities should be presented to practicing social workers through workshops, symposiums and conferences that cover issues of different minority groups (sexual minorities included), as they may not be very accepting of trainings solely focusing on sexual minorities because of culture, religion and personal biases.

Future research can explore how the ethics body of social work in Nigeria (Nigeria Association of Social Workers) can reconcile the differences between the SSMPA and social work ethical codes, to help enable practitioners to navigate the dilemma of working with LGBs.

Further research should be done on the experiences of sexual minorities and social work in Nigeria, to help achieve a better understanding and practice. This can also help enlighten social workers about sexual minorities, and hence propel them to advocate for more humanistic polices protecting these minorities. 


\section{References}

Akogwu, A. (2018). Assessing the human rights implications of the Nigerian law dealing with sexual orientation. LLD Thesis: University of Pretoria. Retrieved from https://repository.up.ac.za/handle/2263/65626

Arimoro, A. E. (2018). When love is a crime: Is the criminalisation of same sex relations in Nigeria a protection of Nigerian culture? Liverpool Law Review, 39(3), 221-238. https://doi.org/10.1007/s10991-018-9217-y

Arimoro, A. E. (2019). The Criminalisation of Consensual Same-Sex Sexual Conduct in Nigeria: A Critique. Journal of Human Rights and Social Work, 4, 257-266. https://doi.org/10.1007/s41134-019-00091-3

American Psychological Association (APA) (2009). Report of the American Psychological Association Task Force on Appropriate Therapeutic Responses to Sexual Orientation. Washington, DC: APA. Retrieved from https://www.apa.org/pi/lgbt/resources/therapeutic-response.pdf Bailey, C. A. (2007). A guide to qualitative field research (2 $2^{\text {nd }}$ ed). Thousand Oaks, California: Pine Forge Press. https://doi.org/10.4135/9781412983204 Braun, V., \& Clarke, V. (2006). Using thematic analysis in psychology. Qualitative Research in Psychology, 3(2), 77101. https://doi.org/10.1191/1478088706qp063oa

Bryman, A. (2016). Social Research Methods (5th ed.). London: Oxford University Press.

Collins, D., Jordan, C., \& Coleman, H. (2013). An introduction to family social work (4th ed.). Brooks/Cole, Cengage Learning.

Daemon, M. (2020). How I almost got killed for being gay in Abuja, Nigeria. Retrieved from https://76crimes.com/2016/

Deane, K., \& Stevano, S. (2016). Towards a political economy of the use of research assistants: Reflections from fieldwork in Tanzania and Mozambique. Qualitative Research, 16(2), 213-228. https://doi.org/10.1177/1468794115578776

Dentato, M. P., Kelly, B. L., Llyold, M. R., \& Busch, N. (2018). Preparing social workers for practice with LGBT populations affected by substance use: Perceptions from students, alumni, and service providers. Social Work Education, 37(3), 294-314. https://doi.org/10.1080/02615479.2017.1406467

Drabble, L., Trocki, K. F., Salcedo, B., Walker, P. C., \& Korcha, R. A. (2016). Conducting qualitative interviews by telephone: Lessons learned from a study of 
alcohol use among sexual minority and heterosexual women. Qualitative Social Work, 15(1), 118-133. https://doi.org/10.1177/1473325015585613

Epprecht, M. (2012). Sexual minorities, human rights and public health strategies in

Africa. African Affairs, 111(443), 223-243. www.jstor.org/stable/41494486

Epprecht, M. (2013). Sources of anxiety about (and among) sexual minorities in

Africa. Board of International Affairs of the Royal College of

Psychiatrists, 10(02), 35-37. https://doi.org/10.1093/afraf/ads019

Epprecht, M., \& Egya, S. E. (2011). Teaching about homosexualities to Nigerian

university students: A report from the field. Gender and Education, 23(4), 367-

383. https://doi.org/10.1080/09540253.2010.491791

Fallon, K. M., Dobmeier, R. A., Reiner, S. M., Casquarelli, E. J., Giglia, L. A., \&

Goodwin, E. (2013). Reconciling Spiritual Values Conflicts for Counselors and Lesbian and Gay Clients. Adultspan Journal, 12(1), 38-53.

https://doi.org/10.1002/j.2161-0029.2013.00014.x

Finnish Immigration Service (2015). Status of sexual and gender minorities in

Nigeria. Retrieved from

https://migri.fi/documents/5202425/5914056/61574_SuuntausLGBTNigeriaFINA L.pdf/c5353c51-bb0f-4cf2-a3d0-

d6f323958058/61574_SuuntausLGBTNigeriaFINAL.pdf

Gay News (2010, August 10). Gay Nigeria activist Bisi Alimi shares his compelling story. Retrieved from https://sdgln.com/news/2010/08/10/bisi-alimis-gaynigerian-story

Gobena, E. B., \& Hean, S. C. (2019). The Experience of Incarcerated Mothers Living in a Correctional Institution with their Children in Ethiopia. Journal of

Comparative Social Work, 14(2), 30-54.

https://doi.org/10.31265/jcsw.v14.i2.247

Hammersley, M., \& Atkinson, P. (2007). Ethnography: Principles in Practice (3rd ed.).

London and New York: Routledge Taylor and Francis Group.

https://doi.org/10.4324/9780203944769

Hepworth, D. H., Rooney, R. H., Rooney, G .D., \& Strom-Gottfried, K. (2013). Direct

Social Work Practice: Theory and Skills, 9th edn. Belmont, CA: Brooks/Cole Cengage Learning.

Human Rights Watch (2016). Tell me where I can be safe: The impact of Nigeria's

Same Sex Marriage (Prohibition) Act. Retrieved from 
https://www.hrw.org/report/2016/10/20/tell-me-where-i-can-be-safe/impactnigerias-same-sex-marriage-prohibition-act

International Federation of Social Workers (2014). Global Definition of Social Work.

Retrieved from https://www.ifsw.org/what-is-social-work/global-definition-ofsocial-work/

International Federation of Social Workers (2020). Nigeria Association of Social Workers Retrieved from https://www.ifsw.org/member-organisation/nigeria/ Jacques, G. (2013). Sexual Minorities in Africa: A Challenge for Social Work. Journal of Gay \& Lesbian Social Services, 25(2), 158-177.

https://doi.org/10.1080/10538720.2013.782835

Jacques, G. (2014). "Coming Out" or Coming in? Social Exclusion of Sexual Minorities in Africa: Challenges for Social Work Education and Practice, Journal of Gay \& Lesbian Social Services, 26(1), 91-110. https://doi.org/10.1080/10538720.2013.829396

Jaffee, K. D., Dessel, A. B., \& Woodford, M. R. (2016). The nature of incoming graduate social work students' attitudes towards sexual minorities. Journal of Gay \& Lesbian Social Services, 28(4), 255-276. https://doi.org/10.1080/10538720.2016.1224210

Kanuha, V. K. (2000). 'Being Native' versus 'Going Native': Conducting Social Work Research as an Insider. Social Work, 45(5), 439-447. https://doi.org/10.1093/sw/45.5.439

Mbah, F., Ebue, M., \& Ugwu, C. (2017). History of Social work in Nigeria. In Okoye, U., Chukwu, N., \& Agwu, P. (Eds.), Social work in Nigeria: Book of readings (pp. 1-14). Nsukka: University of Nigeria Press Ltd. Retrieved from https://www.researchgate.net/publication/331821050_Chapter_1_History_of_So cial_Work_in_Nigeria

McCarty-Caplan, D. (2018). LGBT-Competence in Social Work Education: The Relationship of School Contexts to Student Sexual Minority Competence. Journal of Homosexuality, 65(1), 19-41. https://doi.org/10.1080/00918369.2017.1310547

McNair, R. P., \& Hegarty, K. (2010). 'Guidelines for the Primary Care of Lesbian, Gay, and Bisexual People: A Systematic Review', The Annals of Family Medicine, 8(6), 533-41. https://doi.org/10.1370/afm.1173 
Morrow, S. L. (2005). Quality and trustworthiness in qualitative research in counseling psychology. Journal of Counseling Psychology, 52(2), 250-260. https://doi.org/10.1037/0022-0167.52.2.250

Nalah, A. B., \& Ishaya, L. D. (2013). A conceptual overview of deviance and its implication to mental health: A biopsychosocial perspective. International Journal of Humanities and Social Science Invention, 2(12), 1-9. Retrieved from http://www.ijhssi.org/papers/v2(12)/Version-3/A021203001009.pdf

National Association of Social Workers (2017). Code of Ethics of the National Association of Social Workers (Revised ed.). Retrieved from https://socialwork.utexas.edu/dl/files/academic-programs/other/nasw-code-ofethics.pdf

Nigeria (1990). Criminal Code Act. Retrieved from https://www.refworld.org/cgibin/texis/vtx/rwmain/opendocpdf.pdf?reldoc $=y \& d o c i d=54 f 975004$ Nigeria (2014). Same Sex Marriage (Prohibition) Act, 2013. Retrieved from https://www.refworld.org/pdfid/52f4d9cc4.pdf

Ogbonna, A. (2018, February 6). Buhari declines assent to three bills passed by NASS. Vanguard. Retrieved from https://www.vanguardngr.com/2018/02/buhari-declines-assent-three-billspassed-nass/

Oginni, O. A., Mosaku, K. S., Mapayi, B. M., Akinsulore, A., \& Afolabi, T. O. (2018). Depression and Associated Factors Among Gay and Heterosexual Male University Students in Nigeria. Archives of Sexual Behaviour, 47, 1119-1132. https://doi.org/10.1007/s10508-017-0987-4

Okoye, U. O. (2014). Indigenizing social work education for better social service provisioning in Nigeria. In Omuta, G. E. D. (Ed.), Perspective on social services in Nigeria (pp. 883-895). Ibadan: HEBN Publishers Plc.

Ottoson, D. (2010). State-sponsored homophobia: A world survey of laws prohibiting same-sex activity between consenting adults. An ILGA report, The International Lesbian, Gay, Bisexual, Trans and Intersex Association. Retrieved from https://www.queeramnesty.ch/docs/lLGA_State_ Sponsored_Homophobia_2010.pdf

Pew Research Center (2013). Global Acceptance of Homosexuality. Retrieved from https://www.pewresearch.org/global/2013/06/04/global-acceptance-ofhomosexuality/ 
Novick, G. (2008). Is there a bias against telephone interviews in qualitative research? Research in Nursing \& Health, 31(4), 391-398. https://doi.org/10.1002/nur.20259

Ritchie, J., Lewis, J., McNaughton Nicholls, C., \& Ormston, R. (2014). Qualitative Research Practice. 1st ed. London [u.a.]: SAGE.

Teh, Y. Y., Munisamy, Y., Wong, P. Y. J., Tan, K., Huang, J., \& Yong, J. A. (2018). Singapore social work practice with lesbian, gay, and bisexual clients. International Social Work, 61(1), 51-65. https://doi.org/10.1177/0020872815603785

University of Nigeria (2020). Social Works - Course Modules. Retrieved from https://socialscs.unn.edu.ng/social-works-course-modules/

Vinjamuri, M. (2017). Using reflection and dialogue to prepare social work students for practice with LGBT populations: An emerging pedagogical model. Journal of Gay \& Lesbian Social Services, 29(2), 144-166. https://doi.org/10.1080/10538720.2017.1295896

Weiss-Gal, I. (2008). The Person-in-Environment Approach: Professional Ideology and Practice of Social Workers in Israel. https://doi.org/10.1093/sw/53.1.65

Willis, R., Khambhaita, P., Pathak, P., \& Evandrou, M. (2016). Satisfaction with social care services among South Asian and White British older people: The need to understand the system. Ageing and Society, 36(7), 1364-1387. https://doi.org/10.1017/S0144686X15000422 